\title{
Surgical Treatment of Induced Peri- Implantitis in the Micro Pig: Clinical and Histological Analysis
}

\author{
Gurbhajan Singh, * Robert B. O’Neal, ${ }^{\dagger}$ William A. Brennan, ${ }^{\ddagger}$ Scott L. Strong, ${ }^{\S}$
}

Jack A. Horner, "and Thomas E. Van Dyke"

THE PURPOSE OF THIS PILOT STUDY was to determine if lost osseous support adjacent to root form implants could be regenerated using a guided tissue regeneration technique. Three fixtures were placed in each edentulous mandibular bicuspid region of two micro pigs. A total of 6 fixtures were placed in each pig. Due to the presence of a pathologic condition, which was in no way related to the research, the results of one pig were not evaluated. Following osseointegration, peri-implantitis was induced by the use of ligatures and a soft diet. Three modalities of treatment were performed. Utilizing a surgical flap approach, one third of the fixtures (one per quadrant) were covered with expanded polytetrafluoroethylene (ePTFE) membrane and submerged under the soft tissue complex. The second group of fixtures were submerged under the soft tissue complex with no ePTFE membrane. The control fixtures along with their abutments were debrided and remained non-submerged. All fixtures were debrided using an air-abrasive polishing system. The osseous defects around the fixtures were measured from a fixed reference point at the time of surgery and after obtaining block sections. At euthanasia, 12 weeks after surgery, block sections of fixtures were removed, fixed, dehydrated, embedded, sectioned, and prepared for SEM analysis. The clinical results showed a decrease in the depth of osseous defects adjacent to fixtures submerged with a ePTFE membrane. There was a gain of up to $5 \mathrm{~mm}$ of bone coronally $($ mean $=2.13 \mathrm{~mm}$ ). Histologically, from the base of the defect, $35.6 \%$ of the regenerated bone fill was osseointegrated, the remaining $64.4 \%$ of the regenerated bone fill had a soft tissue interface between bone and fixture. Fixtures that were submerged without an ePTFE membrane gained up to 3 $\mathrm{mm}$ of bone coronally (mean $=1.37 \mathrm{~mm}$ ) with minimal osseointegration $(7.8 \%)$. The control specimens exhibited minimal gain in bone height $(0.87 \mathrm{~mm})$ with no osseointegration. The data suggest that root form fixtures with peri-implantitis may be treated with an ePTFE membrane covered by soft tissue. J Periodontol $1993 ; 64: 984-989$.

Key Words: Dental implants; guided tissue regeneration; osseointegration; surgical flaps; membranes, barrier; polytetrafluoroethylene/therapeutic use.

Dental implants, especially the endosseous type, are becoming accepted as a routine option for replacing missing

\footnotetext{
${ }^{*}$ U.S. Army Dental Activity, Fort Leonard Wood, MO.

${ }^{+}$Currently, private practice, Concord, CA; formerly, Periodontic Residency Program, School of Dentistry, University of Michigan, Ann Arbor, MI. ${ }^{\ddagger}$ Periodontic Residency Program, U.S. Army Dental Activity, Fort Gordon, GA.

${ }^{\S}$ U.S. Army Dental Activity, Landstuhl, Germany.

"Department of Clinical Investigation, Eisenhower Army Medical Center, Fort Gordon, GA.

${ }^{\circledR}$ Department of Periodontics, Eastman Dental Center, Rochester, NY. The opinions or assertions contained in this paper are those of the authors and are not to be construed as official or as reflecting the views of the Department of the Army, Department of Defense, or the United States Government.
}

dentition. ${ }^{1}$ It is estimated that in $1992,300,000$ implants were placed in the United States, and the number is expected to continue to increase in coming years. ${ }^{2}$ While data on the incidence of implant failures are limited, bone loss (peri-implantitis) around some osseointegrated fixtures has been reported. ${ }^{3,4}$ The relationship between peri-implantitis and plaque has not been fully researched. However, a number of studies have demonstrated that the microbiota associated with stable and failing implants are similar to the microbiota of periodontally healthy and diseased teeth, respectively. ${ }^{4-9}$ If this is the situation, the periodontal community will play a major role in the maintenance of soft tissue and osseous support around osseointegrated implants. At the same time, failing implants that demonstrate pro- 
gressive bone loss will present a challenge to the periodontist. Although information is available concerning clinical treatment of the failing implant, little information can be found which provides a histologic view of the healing that has taken place. ${ }^{10-17}$ Surgical techniques were employed in case reports where the osseous defects were grafted with demineralized cortical bone powder, demineralized freezedried bone, and/or hydroxyapatite (40 to $60 \mathrm{mesh}$ ). ${ }^{10-11}$ These studies reported only short-term follow-up and no histology was available.

In recent years there has been considerable interest in the concept of guided tissue regeneration (GTR), which is designed to regenerate the lost attachment apparatus of periodontally involved teeth. ${ }^{18-20}$ This principle was expanded and applied in a series of experimental studies for the regeneration of bone tissue in different types of jaw bone defects, as well as around dental implants. ${ }^{21-24}$ In these studies, a polytetrafluoroethylene (PTFE) membrane was placed over the defect and closely adapted to the bone surface surrounding the defect. Thus, a secluded space was created between the bone defect and the inner surface of the membrane into which cells originating from hard and soft connective tissues could migrate without interference from other competing tissue cell types. In association with dental implants, GTR has a number of applications: 1) ridge augmentation with subsequent placement of a fixture; 2 ) immediate placement of fixtures following extractions; 3 ) sinus lift procedures, either as a preparatory procedure for placing fixtures at a later date or in conjunction with the placement of fixtures; and 4) treating an osseous defect associated with an osseointegrated fixture.

With limited understanding of the incidence and etiology of peri-implantitis and treatment possibilities at hand, a study was undertaken to determine if lost osseous support adjacent to root form fixtures ${ }^{*}$-could be regenerated using a guided tissue regeneration technique.

\section{MATERIALS AND METHODS}

Twelve endosseous fixtures were inserted in the mandibular bicuspid region of two micro pigs (3 bilaterally in each pig). ${ }^{25,26}$ Following fixture osseointegration and abutment placement, peri-implantitis was induced at 6 weeks by means of silk ligatures and a soft diet. Osseous defects associated with the peri-implantitis sites were confirmed clinically and radiographically.

This protocol (DDEAMC 90-4) was approved by the Investigational Review and Animal Use Committees at Dwight David Eisenhower Army Medical Center, Fort Gordon, Georgia.

The attending veterinarian administered the general anesthetics by using a combination of ketamine $(20 \mathrm{mg} / \mathrm{kg})$ and xylozine $(2.5 \mathrm{mg} / \mathrm{kg})$ intramuscularly. General anesthesia was maintained using halothane $(0.05-2.0 \%)$ com-

"Nobelpharma, USA, Chicago, IL.
Table 1. Time Frame for Labeling New Bone Formation

\begin{tabular}{ccc}
\hline Day & Dosage & Drug \\
\hline 0 & $10 \mathrm{mg} / \mathrm{kg}$ & Tetracycline $\mathrm{HCl}$ \\
14 & $10 \mathrm{mg} / \mathrm{kg}$ & Tetracycline $\mathrm{HCl}$ \\
21 & $30 \mathrm{mg} / \mathrm{kg}$ & Alizarin complexone \\
28 & $10 \mathrm{mg} / \mathrm{kg}$ & Tetracycline $\mathrm{HCl}$ \\
42 & $10 \mathrm{mg} / \mathrm{kg}$ & Tetracycline $\mathrm{HCl}$ \\
63 & $10 \mathrm{mg} / \mathrm{kg}$ & Tetracycline $\mathrm{HCl}$ \\
\hline
\end{tabular}

bined with 50\% nitrous oxide and oxygen with an endotracheal tube in place.

Three treatment modalities were utilized to treat periimplantitis. All 3 groups received the following basic treatment: 1) removing the abutment cylinders from the fixtures; 2) reflecting buccal and lingual mucoperiosteal flaps; 3) notching the fixtures on 4 surfaces; 4) removing the granulation tissue from the defects; 5) recording measurements; 6) placing cover screws; and 7) debriding the fixture with a forced air prophylaxis unit. The control group comprised the sites located nearest to the cuspids. After basic treatment, the cover screws were removed and abutment cylinders were replaced.

In the Control Group, comprised of the 4 sites located nearest to the cuspid, the soft tissue flaps were sutured into position around the abutment cylinders.

Experimental Group 1 comprised the sites located between the Control and the Experimental Group 2 sites. Treatment consisted of submerging the fixtures by covering them with the soft tissue complex.

Experimental Group 2 comprised the sites nearest to the molar. These sites were treated by placing an expanded polytetrafluoroethylene (ePTFE) membrane** from which the occlusive collar had been removed to cover the fixture and bony surfaces from a level approximately 2 to $5 \mathrm{~mm}$ apical to the bone crest in all directions, and submerging the fixtures by covering the ePTFE membrane with the soft tissue complex.

The surgical protocol included reflection of full thickness flaps. ${ }^{27}$ Two parallel horizontal incisions were made joining the 2 Experimental Group fixtures sites. Two vertical incisions were then made, one at the distal of the Experimental 2 site and the second in between Experimental 1 and Control fixture sites, to ensure that both the Experimental 2 and Experimental 1 fixture sites were submerged. A single horizontal incision extended from the vertical incision between Experimental 1 and Control fixture sites and extended to the mesial of the cuspid to join a third vertical incision. Defects were measured from a point at the most coronal extent of the fixture to the deepest point of the bony defect on the buccal, lingual, and proximal surfaces of all fixtures. At the time of surgery all fixtures had, at a minimum, the most concave surface below the second thread exposed. The most coronal point of the fixtures were notched

“"W.L. Gore and Associates, Flagstaff, AZ. 
Table 2. Comparison of Osseous Defect Measurements (in mm)*

\begin{tabular}{lcccccc}
\hline & \multicolumn{2}{c}{ Pre-Operative } & & \multicolumn{2}{c}{ Post-Operative } & \\
\cline { 2 - 3 } Group & $\begin{array}{c}\text { Defect } \\
\text { Depths }\end{array}$ & Range & & $\begin{array}{c}\text { Defect } \\
\text { Depths }\end{array}$ & Range & $\begin{array}{c}\text { Bone Gain } \\
\text { Height }\end{array}$ \\
\hline Experimental 2 & $3.00 \pm .92$ & 2 to 5 & & $0.87 \pm 1.1$ & 0 to 3 & 2.13 \\
Experimental 1 & $2.94 \pm .49$ & 2 to 3.5 & & $1.56 \pm 1.34$ & 0 to 3 & 1.37 \\
Control & $3.75 \pm .46$ & 3 to 4.5 & & $2.87 \pm 0.83$ & 2 to 4 & 0.87 \\
\hline
\end{tabular}

* Measurements were taken at 4 notched areas (mesial, distal, facial, and lingual) on each implant.

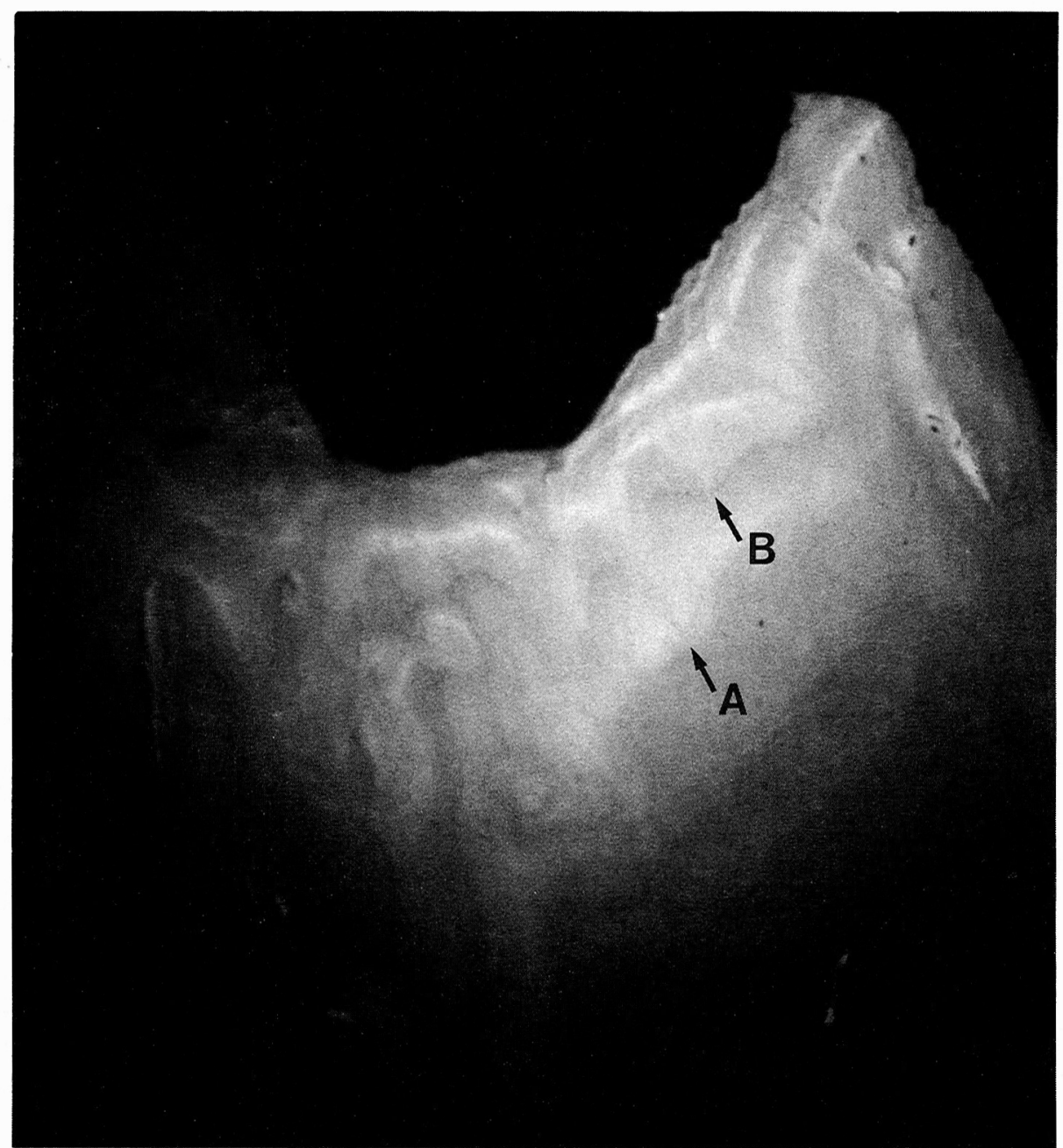

Figure 1. Tetracycline and alizarin red complexone labeling of new bone adjacent to implant fixture 12 weeks post treatment. A: first tetracycline line; B: alizarine red complexone at end of week $3 \times 3$.

with a surgical blade to aid in the reproducibility of the measurement of the defects. Absorbable sutures were used to close the surgical sites.

Tetracycline and alizarin red complexone were given intramuscularly as previously described ${ }^{28-30}$ (Table 1 ) in an effort to label any potential new bone formation.

After the initial 6-week healing period, the ePTFE membrane was surgically removed from the Experimental Group 2 sites. At the end of the 12-week post-operative healing period, the animals were sacrificed. The extent of the defect fill associated with apposition of new bone was measured from the landmarks on the fixtures with the following steps: 1) block sectioning; 2) reflection of the buccal and lingual mucoperiosteal flaps; 3) removal of cover screws; 4) recording measurements; and 5) the taking of radiographs.

During the postsurgical phase, clinical observations were made at regular intervals and it was noted that one animal exhibited an altered healing of the surgical sites. A diag- 


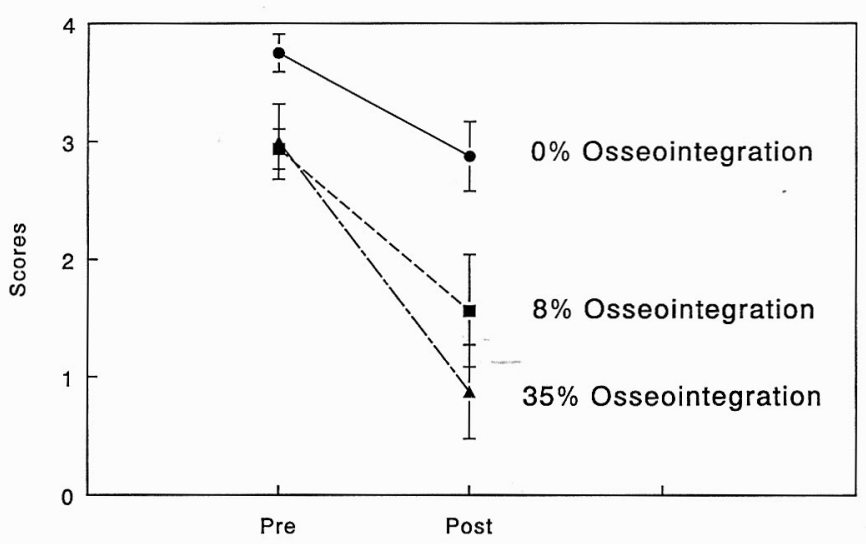

Figure 2. Comparison of the initial osseous defects and the percent of osseointegration for the three groups.

nosis of marrow fibrosis throughout the mandible was made by a veterinary pathologist. The samples from this animal were then excluded from the results of this study leaving only one pig and two samples for each measure.

Following sacrifice with T-61 euthanasia solution, the specimens were fixed in $2 \%$ glutaraldehyde solution for at least 24 hours followed by rinsing with a buffer. The spec-

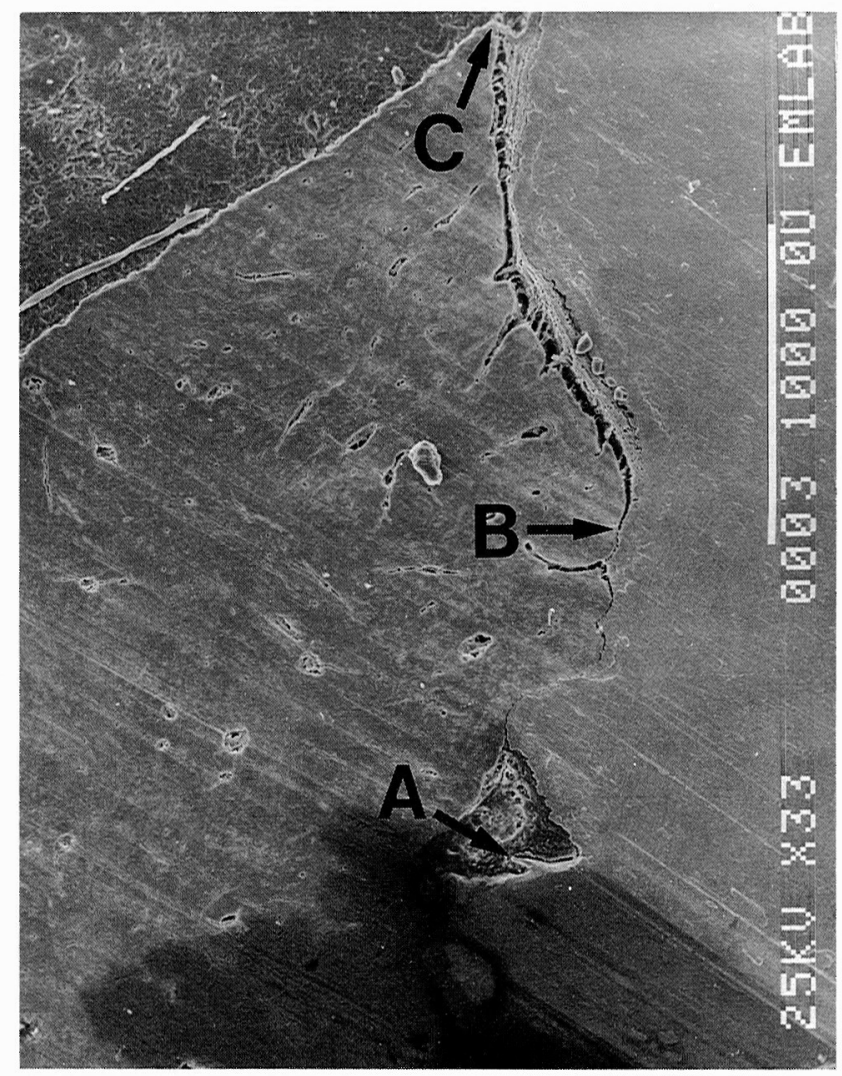

Figure 3. Photomicrograph of experimental 2 fixture. A: most concave point below second thread; $B$ : most coronal point of re-osseointgration; $C$ : coronal height of new bone (original magnification $\times 33$ ).

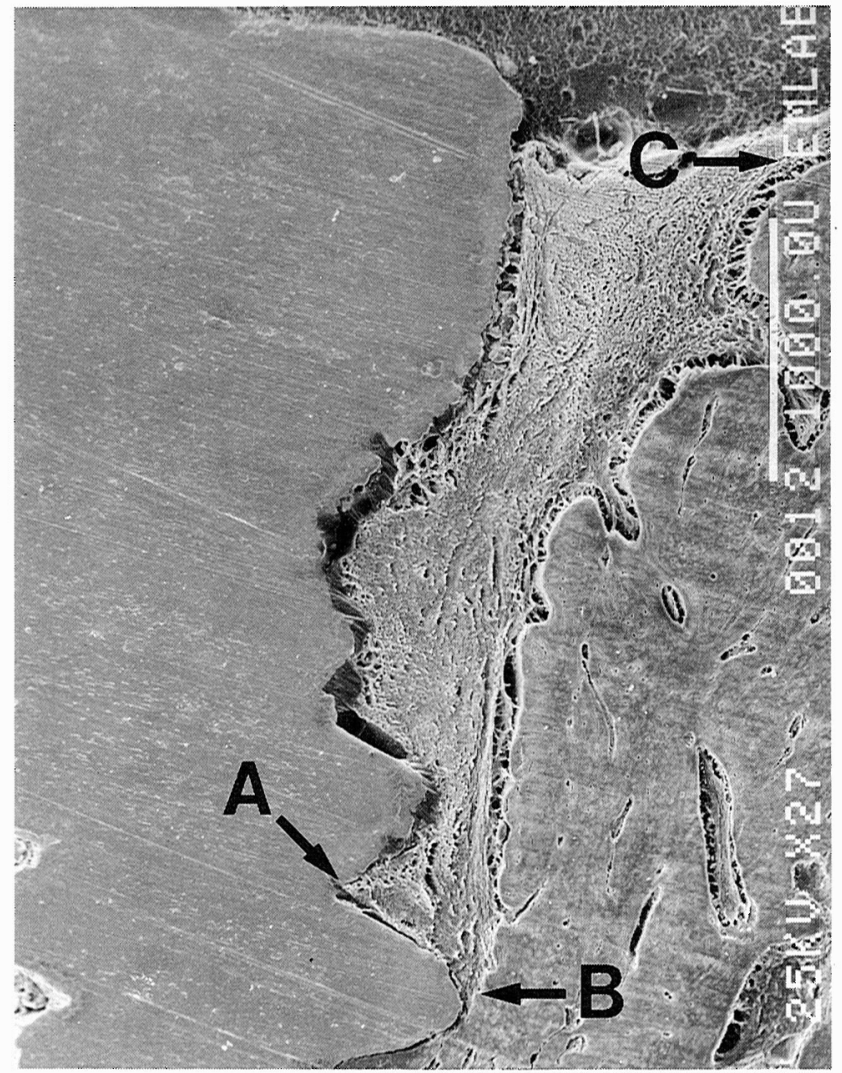

Figure 4. Photomicrograph of experimental 1 fixture. A: most concave point below second thread; B: most coronal point of re-osseointgration; $C$ : coronal height of new bone (original magnification $\times 27$ ).

imens were cut into appropriate sizes for handling purposes. The specimens were then dehydrated using $50 \%, 75 \%$, and 95\% ethanol each with 30-minute rinses followed by $100 \%$ ethanol with 3 changes every 30 minutes. The specimens were embedded in eponate- 12 and polymerized for 24 hours before being sawed with a diamond blade fitted on a Buehler Wafer saw. The final shape of the specimens thus obtained were analyzed using the scanning electron microscope and a digitizer.

The following methods of evaluation were used: 1) clinical measurement analysis of the osseous defects before and after the experimentation; 2) fluorescence analysis; and 3) SEM analysis with quantitative measurement of re-osseointegration using the digitizer.

\section{RESULTS}

Pre- and post-experimental clinical measurements of the osseous defects taken for the three treatment variables revealed that the maximal gain in bone height was achieved when the fixtures were covered with ePTFE membrane under the soft tissue complex (Table 2). There was a gain of up to $5 \mathrm{~mm}$ of bone coronally (mean $=2.13 \mathrm{~mm}$ ) in Experimental 2 sites; a gain of up to $3 \mathrm{~mm}$ of bone coronally $($ mean $=1.37 \mathrm{~mm})$ in Experimental 1 sites, and a gain of minimal bone height $(0.87 \mathrm{~mm})$ in Control sites. Because 


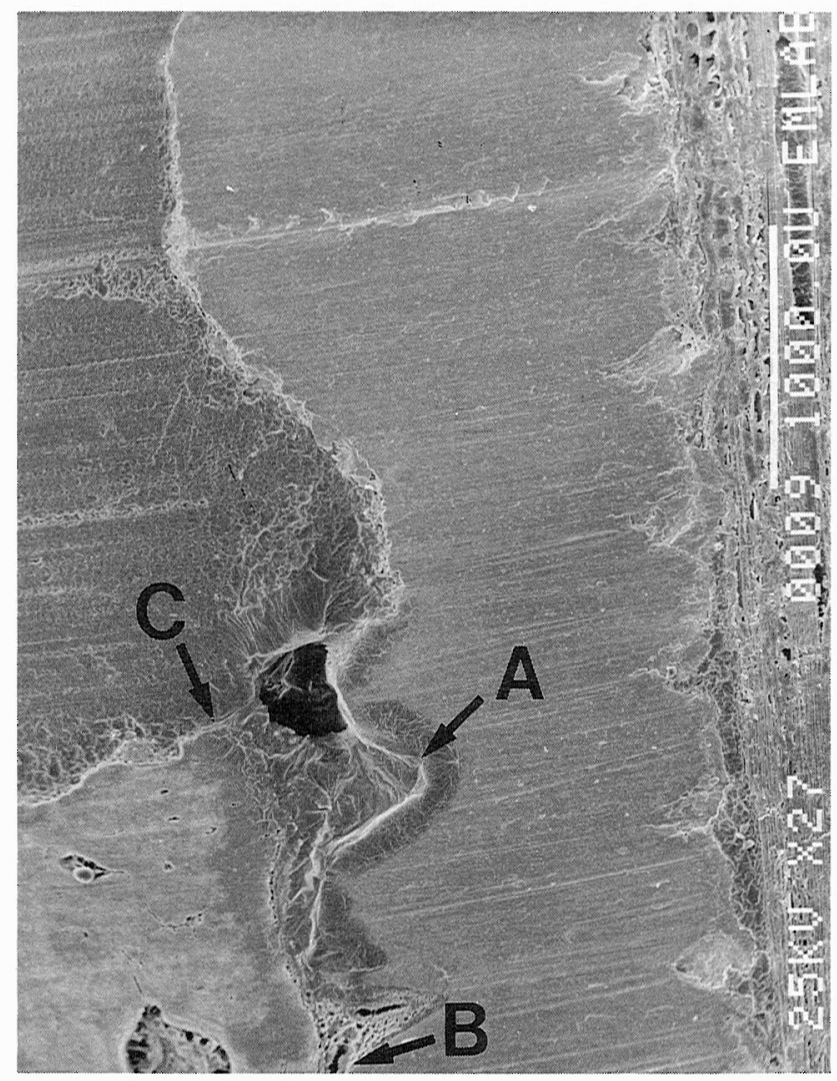

Figure 5. Photomicrograph of control fixture. A: Most concave point below second thread; B: Most coronal point of re-osseointgration; $C$ : Coronal height of new bone (original magnification $\times 27$ ).

of the small sample size, no statistical analysis was done and this is recognized as a shortcoming of this study.

The sectioned samples were analyzed for tetracycline and alizarin red complex band(s) under the fluorescence microscope using the blue light of maximum intensity at $436 \mathrm{~nm}$. Figure 1 shows the various tetracycline bands and one alizarin red complex band of newly-formed bone at a site that was previously diseased.

Quantitative measurement of osseointegration in the newly formed "bone fill" sites was utilized using a Summagraphics Digitizer and Sigma Scan Software. Enlarged photos $\left(8^{\prime \prime} \times 10^{\prime \prime}\right)$ of the SEM sections $(\times 27)$ were given to two independent examiners (SLS and TEV) to demarcate the re-osseointegrated areas. Both examiners demarcated the areas in the photos where bone made direct contact with the fixture surface(s). The most concave point below the second thread was used as a baseline for the beginning of re-osseointegration. Using the digitizer, the total length of the re-osseointegrated site, as well as the total length of the fixture surface that was previously diseased, was obtained. The data from both examiners were averaged. The results (Fig. 2) showed that in Experimental 2 sites, 35.6\% of the sectioned plane had new osseointegration in previously diseased areas of the fixture (Fig. 3). In Experimental 1 sites, only $7.8 \%$ of the sectioned plane had new osseointegration
(Fig. 4). In control sites, there was no new osseointegration (Fig. 5).

\section{DISCUSSION}

This study evaluated the surgical treatment options and provides histological data associated with various methods used to rescue failing implants. Keeping in mind the constraints and limitations of this study, we found that endosseous fixtures showing peri-implantitis may be treated successfully by draping an ePTFE membrane over the defect and then submerging the entire ePTFE membrane and fixture complex under the soft tissue. This may require coronal positioning of the flap.

There are 3 ways to secure the ePTFE membrane. Sutures may be used to secure the membrane to the connective tissue surface of the flap. Alternatively, a hole may be made in the ePTFE with a rubber dam punch; the membrane is secured to the fixture by means of the cover screw. This method may cause the membrane to bunch or not allow it to drape the defect in the desired fashion. Finally, it may not be necessary to secure the membrane in any fashion other than the pressure exerted on it by the overlying soft tissue flap. In this protocol, sutures were used to secure the membrane in place.

While the etiology of failing implants varies, the diagnosis of a failed implant is not complicated. Probing depths and radiographs should be used routinely as diagnostic aids to assist in the diagnosis of failing implants. Even though various studies have looked at the microbiology of failing implants, we still lack information concerning the incidence and causes of peri-implantitis. It would seem that our results might offer a viable treatment option. Again, however, the limitations of this study must be emphasized. This was a small pilot study initially using two micro pigs. The results from one of these animals were not evaluated due to a systemic pathologic aberration which was not associated with the research in any way. It should also be mentioned that, since the sites were not randomly assigned, the results seen could have been due to the location of the treatment rather than the treatment itself. Due to the small sample size, no hypothesis testing could be done which, of course, limits the inferences that can be drawn from this type of study.

\section{Conclusion}

The data suggest that root form fixtures with peri-implantitis may be treated with an ePTFE membrane covered by soft tissue. However, areas of new clinical bone fill were not totally osseointegrated, as evidenced by the histologic finding of a soft tissue interface between bone and fixture in some areas of all specimens. The amount of new clinical bone that was osseointegrated, however, correlates well with the finding of Hale et al., ${ }^{31}$ who found a mean bone contact of $35 \%$ in micropigs after $4 \frac{1}{2}$ months of healing following initial fixture placement in healthy sites. This pilot study shows the possibility of treatment of failing implants with 
ePTFE membranes, but demonstrates the need for further work in this area.

\section{REFERENCES}

1. Adell R, Lekholm U, Rockler B, Branemark PI. A 15-year study of osseointegrated implants in the treatment of the edentulous jaw. Int $J$ Oral Surg 1981;10:387-416.

2. Worthington P. Current implant usage. J Dent Educ 1988;52692695.

3. Worthington P, Bolender CL, Taylor TD. The Swedish system of osseointegrated implants: Problems and complications encountered during a 4-year trial period. Int J Oral Maxillofac Implants 1987;2:7784.

4. Becker W, Becker BE, Newman MG, Nyman S. Clinical and microbiologic findings that may contribute to dental implant failure. Int $J$ Oral Maxillofac Implants 1990;5:31-38.

5. Newman MG, Flemmig TF. Periodontal considerations of implants and implant associated microbiota. J Dent Educ 1988;52:737-744.

6. Apse P. Cross-sectional clinical and microbiological investigation of peri-implant and periodontal status. J Dent Res 1988;67(Spec. Issue):287(Abstr. 1398).

7. Brandes R, Beamer B, Holt SC, Kornman K, Lang NP. Clinicalmicroscopic observation of ligature induced "periimplantitis" around osseointegrated implants. J Dent Res 1988;67(Spec. Issue):287(Abstr. 1397).

8. Holt R, Newman MG, Kratochvil F, et al. The clinical and microbial characterization of peri-implant environment. J Dent Res 1986;65(Spec Issue):247(Abstr. 703).

9. Mombelli A, Van Oosten MAC, Schurch E, Lang NP. The microbiota associated with successful or failing osseointegrated titanium implants. Oral Microbiol Immunol 1987;2:145-151.

10. Gammage DD, Bowman AE, Meffert RM. Clinical management of failing dental implants: four case reports. J Oral Implantol 1989;15:124 131.

11. Lozada JL, James RA, Boskovic M, Cordova C, Emanuelli S. Surgical repair of peri-implant defects. J Oral Implantol 1990;16:42-46.

12. Kraut RA, Judy KWM. Implant preservation using guided tissue augmentation membrane and porous hydroxyapatite. Int $J$ Oral Implant 1991;8(2):55-58.

13. Jovanovic SA, Spiekermann $H$, Richter EJ. Bone regeneration around titanium dental implants in dehisced defect sites: A clinical study. Int J Oral Implant 1992;7:233-245.

14. Lehmann B, Bragger U, Hammerle CHF, Fourmousis I, Lang, NP. Treatment of an early implant failure according to the principles of guided tissue regeneration. Clin Oral Implant Res 1992;3:42-48.

15. Zablotsky M. The surgical management of osseous defects associated with endosteal hydroxyapatite-coated and titanium dental implants. Dent Clinics North Amer 1992;36:117-150.

16. Meffert RM. How to treat failing and ailing implants. Implant Dent 1992;1:25-33.
17. Zablotsky M, Diedrich D, Meffert RM. Detoxification of endotoxincontaminated titanium and hydroxyapatite-coated surfaces utilizing various chemotherapeutic and mechanical modalities. Implant Dent 1992;1:154-158.

18. Nyman S, Gottlow J, Karring T, Lindhe J. The regenerative potential of the periodontal ligament. An experimental study in the monkey. $J$ Clin Periodontol 1982;9:257-265.

19. Gottlow J, Nyman S, Karring T, Lindhe J. New attachment formation as the result of controlled tissue regeneration. $J$ Clin Periodontol 1984;11:494 $=503$.

20. Magnusson I, Nyman S, Karring T, Egelberg J. Connective tissue attachment formation following exclusion of gingival connective tissue and epithelium during healing. $J$ Periodont Res 1985;20:201208.

21. Dahlin C, Sennerby L, Lekholm U, Lindhe A, Nyman S. Generation of new bone around titanium implants using a membrane technique: An experimental study in rabbits. Int $J$ Oral Maxillofac Implants 1989;4:19-25.

22. Seibert J, Nyman S. Localized ridge augmentation in dogs: A pilot study using membranes and hydroxyapatite.J Periodontol 1990;61:157165.

23. Becker W, Becker B, Handlesman M, et al. Bone formation at dehisced dental implant sites treated with implant augmentation material: a pilot study in dogs. Int $J$ Periodontics Restorative Dent 1990;10:93-101.

24. Balshi TJ, Hernandez RE, Cutler RH, Hertzog CF. Treatment of osseous defects using Vicryl mesh (Polyglactin 910) and the Branemark implant: A case report. Int J Oral Maxillofac Implants 1991;6:8791.

25. Weaver ME, Soransen FM, Jump EB. The miniature pig as an experimental animal in dental research. Arch Oral Biol 1962;7:17-24.

26. Jump EB, Weaver ME. The miniature pig in dental research. Swine in biomedical research. Proceedings from Symposium at the Pacific Northwest Laboratory, Richland, Washington. July 19-22, 1965.

27. Bhaskar SN, Cutwright DE, Beasley JD, Perez B, Hunsuck EE. Healing under full and partial thickness mucogingival flaps in miniature swine. J Periodontol 1971;42:322-330.

28. Skinner HC, Nalbandian J. Tetracyclines and mineralized tissues: Reviews and perspectives. Yale J Biol Med 1975;48:377-397.

29. Treharne R, Brighton $C$. The use and possible misuse of tetracycline as a vital stain. Clin Ortho Related Res 1979;140:240-246.

30. Tam C, Anderson W. Tetracycline labeling of bone in vivo. Calcified Tissue Inter 1980;30:121-125.

31. Hale TM, Boretsky BB, Scheidt MJ, McQuade MJ, Strong SL, Van Dyke TE. Evaluation of titanium dental implant osseointegration in posterior edentulous areas of micro swine. J Oral Implantol 1991;17(2):118-124.

Send reprint requests to: Director, Periodontic Residency, US Army Dental Activity, Fort Gordon, GA 30905.

Accepted for publication March 27, 1993. 